\title{
BRITO, Celso de. A roda do mundo: A Capoeira Angola em tempos de globalização
}

\section{Geslline Giovana Braga}

\section{(2) OpenEdition \\ 1 Journals}

Edição electrónica

URL: http://journals.openedition.org/aa/3564

DOI: 10.4000/aa.3564

ISSN: 2357-738X

Editora

Programa de Pós-Graduação em Antropologia Social (UnB)

\section{Edição impressa}

Data de publição: 1 junho 2019

Paginação: 359-363

ISSN: 0102-4302

\section{Refêrencia eletrónica}

Geslline Giovana Braga, «BRITO, Celso de. A roda do mundo: A Capoeira Angola em tempos de globalização», Anuário Antropológico [Online], v.44 n. 1 | 2019, posto online no dia 06 julho 2019, consultado o 28 abril 2021. URL: http://journals.openedition.org/aa/3564 ; DOI: https://doi.org/ 10.4000/aa.3564

\section{(c) ()) (9)}

Anuário Antropológico is licensed under a Creative Commons Atribuição-Uso Não-Comercial-Proibição de realização de Obras Derivadas 4.0 International. 


\title{
BRITO, Celso de. A roda do mundo: A Capoeira Angola em tempos de globalização. Curitiba: Apris, 2017.
}

\author{
Geslline Giovana Braga \\ Universidade Federal do Paraná - Brasil
}

A roda do mundo: a Capoeira Angola em tempos de globalização é fruto da dissertação que Celso de Brito defendeu em 2010 no Programa de Pós-Graduação em Antropologia Social da Universidade Federal do Paraná. Dividido em quatro capítulos, o livro descreve os sistemas de linhagens da Capoeira Angola a partir de grupos instalados em Curitiba nos anos 1990. A pesquisa etnográfica realizada pelo autor estende-se ao Grupo de Capoeira Angola Cabula (GCAC) na França, com o objetivo de mostrar fluxos de capoeiristas em tais circuitos, permeados por noções de globalização. Ao longo do trabalho, Brito retoma as discussões de sistemas de linhagem na antropologia, a partir de clássicos como A. R. Radcliffe-Brown, para desenhar as linhagens e os fundamentos identitários da Capoeira Angola, explora o conceito de "glocalização" de Roland Robertson e, por fim, categoriza os "fluxos culturais" dos grupos nos termos de Arjun Apparudai.

No Capítulo 1, "Entre o global e o local”, o antropólogo apresenta o seu pertencimento ao universo da Capoeira, descrevendo sua iniciação na Capoeira Regional, passando pela Capoeira Contemporânea e sua conversão à Capoeira Angola. Tais vertentes são explicadas ao longo do texto, como constituidoras das diferenças de fundamentos da prática da capoeira. A Capoeira Regional de Mestre Bimba seria a vertente que sistematizou a capoeira; a Capoeira Angola de Mestre Pastinha como vertente ligada às tradições africanas; e a Capoeira Contemporânea como uma fusão das vertentes. Brito é um "estudioso-jogador", termo usado por Carlos Eugênio Libano Soares (1995), no livro A negregada instituição: os capoeiras no Rio de Janeiro, para nomear capoeiristas que também se dedicam a pesquisas acadêmicas sobre Capoeira. Mestre Luiz Renato (1998), no artigo "Mitos, controvérsias e fatos: construindo a história da Capoeira", diz ser de grande contribuição às ciências humanas que capoeiristas sejam pesquisadores acadêmicos, no entanto, observa que esses podem legitimar a visão da própria linhagem ou grupo: "a inserção do pesquisador do campo - no sentido sociológico de Pierre Bourdieu - da Capoeira, o que, sem dúvida alguma, interfere nas posições que este assume quanto a aspectos doutrinários da luta” (1998: 2). 
Ainda nesse primeiro capítulo, Brito indica seus referenciais teóricos, para tratar de temas como cultura e identidade, tradição e transnacionalismo. Identifica a importância da noção de "fundamento" para a Capoeira Angola em sua expansão sem choque com a tradição, organizando relações sociais e mobilidade ao deslocar-se. Ao enunciar suas discussões, empresta outras noções já aplicadas à Capoeira como "globalização” e “diáspora”, referenciando Daniel S. Ferreira Granada (2004) e Maurício Barros de Castro (2007). E, assim, introduz o conceito de "glocalização" de Roland Robertson (2000). O autor demonstra como tal conceito serviu para explicar os fluxos do Tango e do Hip Hop, e como este lhe parece ideal para pensar a difusão da Capoeira Angola em diferentes lugares com os mesmos fundamentos originários. Brito cita e descreve as noções de Arjun Appadurai, que resgatará no último capítulo, explicando suas relações com os "fluxos culturais" marcados pelas mídias e pelos deslocamentos populacionais. E com o "trabalho de imaginação", descreve as cinco dimensões desses fluxos cunhados pelo antropólogo indiano: ethnoscapes, technoscapes, finascapes, mediascapes e ideoscapes. Assinala não ser o primeiro a acessar tais conceitos para explicar a Capoeira transnacionalizada, cita Mônica Acetti (2010) e a noção de que a capoeira "dissemina-se pelo mundo a partir de "ethnoscapes'” (Brito, 2017: 53), sistematizados no "triângulo de hibridização" do tipo GOL - Global, Origem, Local - mostrando como tais fontes culturais são simétricas para expansão da Capoeira.

No segundo Capítulo, "Origens e linhagens", baseado nos clássicos de A. R. Radcliffe-Brown e E. E. Evans-Pritchard, Brito empreende o esforço de elaborar um sistema de linhagens da Capoeira Angola, a partir de Mestre Pastinha. Considerando a "forma estrutural do sistema", o autor constrói dois gráficos, um denominado "Forma estrutural do sistema de linhagem da Capoeira Angola" e outro, "Estrutura do sistema de linhagem da Capoeira Angola”. Esses empenhos sistematizadores são corajosos, pois as discussões sobre tais sistemas de linhagem são controversas e permeadas pelas concepções de cada grupo.

Ainda no Capítulo 2, Brito considera que as identidades são construídas a partir dos fundamentos e classificadas em quatro diferentes dimensões, observando os sinais diacríticos de alteridade em relação progressiva com a Capoeira Regional, as linhagens, os grupos e os núcleos. Para o autor, os fundamentos identitários da primeira dimensão são relações de alteridade com a Capoeira Regional: o uso de calçados, a formação da orquestra, a gestão da violência e as "chamadas de Angola"; os da segunda marcam descontinuidades dentro das linhagens e estão ligados às diferentes 
formas de organizar a orquestra; os da terceira são sutis, como a cor e símbolos das roupas, e marcam as diferenças entre grupos de uma mesma linhagem; enquanto os da quarta dimensão são as diferenças dos núcleos pertencentes aos mesmos grupos. Tal empreendimento de categorização depreende da lógica da própria linhagem do autor, que vem do Mestre Moraes, como mestre de grupos atuantes na cidade de Curitiba/PR. As quatro dimensões relacionam-se aos gráficos acima mencionados, pois exemplificam as relações entre as vertentes, as linhagens e os grupos, a partir dos mestres.

No Capítulo 3, "Angoleiros emergentes: a formação de núcleos de Capoeira Angola na França e no Brasil”, Brito avisa que a expressão "angoleiros emergentes" foi cunhada por Rosangela Costa Araújo (2004), em sua tese de doutorado A Capoeira Angola da escola pastiniana como prática educativa. Essa expressão foi utilizada para mostrar como os novos grupos se legitimam diante dos mais antigos. Celso Brito delimita a análise aos grupos de Capoeira Angola de Curitiba, fundados nos anos 1990 e ligados às linhagens de Mestre Moraes e ao Grupo GEAC de Lyon, de Mestre Barba Branca. O autor descreve a fundação, o desenvolvimento e as pontes entre as duas cidades, considerando as filiações e apadrinhamentos, evidenciando como, mesmos distantes, os dois grupos se mantêm fiéis aos fundamentos da Capoeira Angola a que estão vinculados, relacionados às formas do jogo, da orquestra, das vestes e das cores.

O Capítulo 4, "Glocalização dos fundamentos rituais, deslocamentos e sociabilidade”, é o mais etnográfico. Conforme os fluxos culturais de A. Appadurai, Brito realiza o esforço de designar os atos dos capoeiristas de Lyon do GCAC a partir da terminologia scapes. Inicialmente, Brito recorre a Jacques Le Goff (2002) e David Harvey (2008) para fundamentar a noção de que os jovens parisienses ainda estão impactados por Maio de 68 e têm uma sedução pela contracultura como oposição à racionalização ocidental. Tais afirmações também poderiam considerar o contexto francês atual com os "fluxos" produzidos pelos contextos migratórios e também com a significativa presença de grupos de outras vertentes de Capoeira na França e na Europa, iniciadas nos anos 1980 e intensificadas nos últimos anos.

Como "médiascapes", Brito relata como os capoeiristas do grupo francês conduzem um aprendizado através de meios midiáticos, com materiais audiovisuais sobre a Capoeira Angola e, também, sobre a brasilidade de forma geral, em documentário e ficção. Observando como os materiais audiovisuais são usados nas lógicas tradicionais da Capoeira Angola, ele conta que um de seus informantes mantinha seus 
arquivos de vídeos ordenados a partir das linhagens e, com isto, era capaz de reconhecer os jogos de cada mestre e seus alunos. Também descreve uma roda na qual a orquestra de Barba Branca, mestre do GCAC, foi projetada junto à orquestra que tocava na roda, propiciando assim uma interação midiática com o mestre que estava em Salvador, à distância do grupo.

Brito ainda observa que há uma sedução na Capoeira em função de suas formas de sociabilidade, já que os praticantes franceses creem ser diferentes da sociedade francesa, assim como a resistência e o contrapoder são assinalados pelos praticantes. Em “Ethnoscapes”, Brito demonstra, por meio da narrativa de seus interlocutores, como a religiosidade afro-brasileira é incorporada aos grupos pelas narrativas dos integrantes, mesmo não sendo um ensinamento apreendido com o mestre na França e, sim, fruto de experiências no Brasil. Ao citar Peter Fry (1982) e Daniel S. Ferreira Granada (2004), Brito considera que os símbolos nacionais são tencionados entre os angoleiros de Lyon não só como símbolos étnicos, mas místicos:

O que os lionenses estão nos mostrando, com a sua concepção do ritual da Roda da Capoeira Angola como religare, é que um novo cosmopolitismo moderno, muito peculiar, se forma na Capoeira Angola, mediante a linguagem do "espiritual" e do "sagrado" (: 162).

Por fim, Brito conclui:

A roda do mundo representa, portanto, o lócus no qual se articulam o ritual da "Roda de Capoeira Angola" e o "sistema de linhagem", o "local" e o "global", a "tradição" e a "modernidade", o "sagrado" e o "profano", ou, então, em outras palavras, a "Capoeira Angola glocalizada" (: 214).

Tal frase sintetiza a necessidade de categorização do autor ao longo do texto, enquanto os relatos etnográficos mostram fluidez e atravessamentos na consolidação de grupos transnacionalizados.

Com isto, a noção de globalização poderia propor discussões por um viés étnico-racial, fortuito no texto; e na mesma proporção, o conceito de "glocalização" tem objetivos mais fluidos do que a reafirmação de dicotomias expressas no texto, como tradição e modernidade ou sagrado e profano, por exemplo. Independente das delimitações da pesquisa, as questões étnico-raciais perpassam a Capoeira, são 
estruturantes e estão nos fundamentos dos grupos, algo esquivado pelo autor.

O livro apresenta uma pesquisa em profundidade sobre a Capoeira Angola transnacionalizada, a partir de grupos de Curitiba, o que é relevante por mostrar a difusão da Capoeira também no Brasil, e da França, revelando a expansão da Capoeira ao redor do mundo. O corpo teórico utilizado no livro ora serve aos anseios do pesquisador, ora aos anseios do jogador que pertence a um grupo. Esse ponto faz o livro ter relevância também para os estudos sobre métodos etnográficos, refletindo sobre o "pesquisador-jogador" e a "observação participante”. Essa é uma leitura propositiva para antropólogos e desafiante para capoeiristas de todas as vertentes.

Recebido: 30/09/2018

Aprovado: 15/01/2019

Geslline Giovana Braga é graduada em Comunicação Social e Sociologia, especialista em fotografia. Mestre em Antropologia Social (UFPR) e Doutora em Antropologia Social (USP). Atualmente realiza estágio pós-doutoral em Geografia Cultural na UFPR. Foi professora substituta do Departamento de Antropologia da UFPR. É realizadora de documentários. Orcid: 0000-0002-1618-6239. Contato: geslline@gmail.com 